\title{
Editorial: a Very Special Issue
}

\author{
Donald A. Hantula ${ }^{1}$
}

Published online: 9 May 2016

(C) Association for Behavior Analysis International 2016

This issue of The Behavior Analyst (TBA) marks changes for the journal, some of which are reflected in this issue, and others of which are on the temporal horizon. First we have a new editorial team. Second, we have some possible new directions to explore for $T B A$. Third, we have a new issue of $T B A$.

\section{Give Thanks First}

Cicero teaches us that gratitude is the greatest of virtues. I thank the outgoing editorial team for their excellent contributions to the journal. Editor Matt Normand; Associate Editors: Jesse Dallery, Rachel Thompson; and editorial board members: Erik Arntzen, Jason C. Bourret, Iser DeLeon, Scott T. Gaynor, Iver Iverson, M. Christopher Newland, Denis O'Hora, David W. Schaal, Claire St. Peter. These individuals worked hard vetting and editing manuscripts that enlightened and informed TBA's readers.

I thank the new editorial team for volunteering their time and expertise. We are fortunate to have two outstanding new Associate Editors, Tom Critchfield and Erin Rasmussen whose work spanning basic, applied, theoretical and professional topics in Behavior Analysis is well-known to all ABA-I members. I welcome new editorial board members Christine Hoffner Barthold, Asle Fagerstrøm, Matthew Locey, Elizabeth R. Lorah, Laura Methot, Jorge M. Oliveira-Castro, Thomas Waltz, and Richard Yi. Our team of current and new board members gives $T B A$ an exceptional amount of breadth and depth of behavior analytic expertise.

I also thank the authors whose work appears in these pages, will appear in forthcoming issues, and is currently under review by $T B A$. While the editorial team cannot promise that every paper will be eventually accepted, we can promise that all suitable papers will undergo a prompt, fair and rigorous review process.

Donald A. Hantula

Hantula@temple.edu

1 Department of Psychology, Temple University, Weiss Hall, 1701 N 13 St, Philadelphia, PA 19122-6085, USA 


\section{Quo Vadis $T B A$ ?}

The Behavior Analyst publishes a wide range of conceptual, historical, methodological, philosophical and theoretical papers in behavior analysis. Where the journal fits in the wider array of behavior analytic journals is a matter of continuing discussion. Clearly there is an increasing demand for behavior analytic research and scholarship (or at least for outlets for this work). A multitude of possible venues for behavior analytic research is a good thing, but with increased publication opportunities come questions of market saturation, journal identity, publication quality, and sheer exhaustion from trying to keep up with it all.

Sometimes it is hard to believe that merely 60 years ago, the Journal of the Experimental Analysis of Behavior was founded because behavior analysts had virtually nowhere to publish their research (Laties, 2008). In 2016 we have an abundance of venues for behavior analytic research and scholarship. Currently ABA-I publishes The Behavior Analyst, The Psychological Record, The Analysis of Verbal Behavior and Behavior Analysis in Practice. The OBM Network (a special interest group of ABA-I) publishes the Journal of Organizational Behavior Management. SABA publishes the aforementioned Journal of the Experimental Analysis of Behavior and the Journal of Applied Behavior Analysis. APA publishes Behavior Analysis: Research and Practice. Many other journals such as Behavior and Philosophy, Behavioral Interventions, Behavioral Pharmacology, Behavioural Processes, Behavior Modification, Behavior and Social Issues, European Journal of Behavior Analysis, Experimental and Clinical Psychopharmacology, Japanese Journal of Behavior Analysis, Journal of Behavioral Education, Journal of Contextual Behavioral Science, Journal of Positive Behavior Interventions, Psychopharmacology, Revista Mexicana de Análisis de la Conducta, all publish behavior analytic research and scholarship. Many other more mainstream journals regularly publish behavior analytic work, and some even devote special issues to behavior analytic topics (e.g.; The Behavior Analysis of Consumer Choice, Journal of Economic Psychology, and Operant Behavioral Economics, Managerial and Decision Economics (Foxall, 2003, 2015).

As ABA-I's flagship journal, TBA must fill a number of important roles. TBA should inform the ABA-I membership about important research and scholarship in behavior analysis, writ large. With the marked increase in behavior analytic publications, it is very easy for individual behavior analysts to become overly focused on their own interests and miss the wide scope and diversity of behavior analytic work. Indeed, a glance at the annual ABA-I meeting program shows the outstanding breadth and depth of behavior analysis today. TBA will bring the best of behavior analytic scholarship to its readers. To that end, we invite behavioral scientists to submit review, theory and methodology papers that summarize and review critically an area of research or application, and point us in future directions.

We expect that review papers will be data based and will employ the most current quantitative and meta-analytic methods. For example, consider the variety of quantitative methods available for summarizing small-n research designs ((Allison \& Gorman, 1993; Pustejovsky, 2015; Pustejovsky, Hedges, \& Shadish, 2014; Shadish, 2014; Solomon, Howard, \& Stein, 2015; Vannest \& Ninci, 2015)). Narrative reviews, "box scores," and percent change measures are minimally informative, and often misleading. Behavior analysis is an empirical science; as such reviews should capitalize on the rich data in the field. Conclusions in behavior analytic work that are not based on data are no more than suspected hypotheses in transition. 
Theory papers should stretch the boundaries of behavior analytic theory. Behavior analysis rests on a small set of simple, yet powerful principles. Those who work in the applied world have sculpted basic findings in behavior analysis into effective interventions for countless socially important behavioral challenges, or have used these principles to understand sometimes puzzling behavior. Behavior analytic theory did not begin and end in 1913, 1938, 1957, or even 2015. Indeed, theoretical work in behavior analysis is robust, challenging and laying the foundation for future research and application; for a representative sample of some excellent contemporary theoretical work see the following (Hayes, 2013; Hughes \& Barnes-Holmes, 2016; McDowell \& Calvin, 2015; Nevin \& Shahan, 2011).

TBA should also inform behavior analysts about connections between behavior analysis and other fields and disciplines. These types of papers should show a clear command of the literature and issues in both behavior analysis and the field in question. It is not enough to simply point out that "field $\mathrm{x}$ " has something to do with behavior, therefore behavior analysis is relevant. Instead, show how a behavior analytic perspective may generate some novel (and non-obvious) insights. Such papers should educate $T B A$ readers about the field in question, and demonstrate how behavior analysis can solve some of its thorny problems (for an exemplar with economics, see (Herrnstein, 1990); and for an exemplar with consumer behavior see (Foxall, 2010); Alternatively, such papers should educate readers about how the field in question can inform behavior analytic research (for an exemplar with economics see (Hursh, 2014), or how behavior analysis and the field are asking complementary questions (for an exemplar with behavioral ecology see (Fantino, 1985). These papers should be written so that they are valuable and informative to both behavior analysts and to and those who work in the field in question.

In keeping with these aims, we intend to publish more book reviews in $T B A$. Reviews of books in or about behavior analysis are welcome, of course. Such reviews should critically and fairly evaluate the book and place its contribution in the context of the field at large. We also welcome reviews of books that are not necessarily behavior analytic in nature, but may have relevance for behavior analysis. These reviews should not only offer a fair critical appraisal of the book, but demonstrate clearly how and why this book should be of interest to TBA's readers. We will expedite the review process for book reviews.

$T B A$ is not limited to one particular type of paper. We welcome and encourage innovative scholarship that pushes the boundaries of scientific discourse. Should scholarship in the $21 \mathrm{st}$ century be limited to text? Or, perhaps another way to think about the issue is to ask "what does the technology we have available to us now allow us to do that we could not do before?" Submit something new and innovative to $T B A$, and let us learn together.

Behavior analysis is a very wide-ranging discipline. TBA has to both bring behavior analysis to behavior analysts, but also has to bring behavior analysis to the rest of the world. This is why we want to feature papers that showcase the best of behavior analysis as well as papers that make clear, meaningful connections between behavior analysis and other disciplines. We want TBA papers to be well read, and well cited. This latter criteria is a bit cynically pragmatic, but nonetheless important in the current academic environment. Journal metrics such as impact factor and other purported performance measures are well known to be unreliable, invalid and can be just plain wrong (Brumback, 2012; EyreWalker \& Stoletzki, 2013; Hantula, 2005), however they still exert an inordinate influence 
over gullible administrators and the potential authors who have to answer to them. Too many institutions and funding agencies use journal metrics as the primary or sole indicator of scholarly "performance" "productivity" or "quality." It does a great disservice to early or mid-career scholars if their work appears in a journal with low metrics. TBA cannot attract high quality manuscripts from promising scholars if the journal metrics are unacceptable. Further, journals with low metrics cannot effectively advance a field. Too often people may make a category error and associate low journal metrics in a field with low importance of that field. What this means operationally is that $T B A$ submissions should have broad appeal both inside and outside of behavior analysis. TBA, and behavior analysis in general, cannot survive in an echo chamber. Behavior analysts writing about the eccentricities of behavior analysis for other behavior analysts and no one else is not a sustainable enterprise. It is possible for papers that might interest readers will be judged not suitable for publication in $T B A$ because their contribution is not scholarly in the sense of aiming to promote future academic work.

\section{Special Sections and a Very Special Issue}

We present a wide variety of papers in this issue. The lead paper by Mickey Keenan may be one of the shortest we publish in page length, but length is not always best measured by page count. Take out your tablet or smart phone, update the QR code reader, and enjoy the presentation. Is this the future of scientific publishing? Perhaps....we shall see. Louise Barrett's paper, based on her B. F. Skinner lecture does an excellent job of connecting behavior analysis with larger issues in science, especially that of anthropomorphism and its follies. Then we go quickly from the future to the past. Takayuki Sakagami and Andy Lattal take us back to our history with a delightful description of one the first operant chambers used in Japan. Papers like this are more than mere curiosities; studying our past allows us to define our future.

This issue then proceeds to two special sections. The special section on leadership and cultural change, edited by Ramona Houmanfar and Mark Mattaini, is based on an innovative seminar that ran before and during the 2014 ABA-I meeting. Some of the papers from the seminar appeared in the 2015 volume of the Journal of Organizational Behavior Management (Houmanfar \& Mattaini, 2015) as detailed in the editorial introduction to this section. The papers in this special section of $T B A$ are a continuation of this important discussion. The special section on graduate training programs contains papers solicited and edited by Jim Carr. The issue concludes with an excellent book review. James MacDonnall reviews Staats' volume The Marvelous Learning Animal. Staats' book is a nice complement to Barrett's paper in this issue, and it also takes on a bigger issue, one that has challenged psychology for a century; the centrality of learning in human development and potential.

We hope that the papers in this issue of The Behavior Analyst interest you, inform you, and inspire you. If you have ideas, proposals, or questions about possible formats, submissions, special sections, special issues book reviews, or books to be reviewed, please send an email to hantula@temple.edu. We look 
forward to working with our current and potential future authors and readers to bring the best of behavior analysis to the world.

Acknowledgments I thank Erin Rasmussen and Tom Critchfield for their comments on this editorial.

\section{References}

Allison, D. B., \& Gorman, B. S. (1993). Calculating effect sizes for meta-analysis: the case of the single case. Behaviour Research and Therapy, 31, 621-631.

Brumback, R. A. (2012). '3. 2. 1. Impact [factor]: target [academic career] destroyed!': just another statistical casualty. Journal of Child Neurology, 27(12), 1565-1576. doi:10.1177/0883073812465014.

Eyre-Walker, A., \& Stoletzki, N. (2013). The assessment of science: the relative merits of post-publication review, the impact factor, and the number of citations. PLoS Biology, 11(10). doi:10.1371/journal.pbio.1001675.

Fantino, E. (1985). Behavior analysis and behavioral ecology: a synergistic coupling. Behavior Analyst, 8(2), $151-157$.

Foxall, G. R. (2003). The behavior analysis of consumer choice: an introduction to the special issue. Journal of Economic Psychology, 24(5), 581-588. doi:10.1016/s0167-4870(03)00002-3.

Foxall, G. R. (2010). Invitation to consumer behavior analysis. Journal of Organizational Behavior Management, 30(2), 92-109. doi:10.1080/01608061003756307.

Foxall, G. R. (2015). Operant behavioral economics. Managerial and Decision Economics. doi:10.1002/mde. 2712.

Hantula, D. A. (2005). The impact of JOBM: ISI impact factor places the Journal of Organizational Behavior Management third in applied psychology. Journal of Organizational Behavior Management, 25(3), 1-15. doi: $10.1300 / \mathrm{J} 075 \mathrm{v} 25 \mathrm{n} 03$ _ 01.

Hayes, L. J. (2013). Theory and philosophy: future directions. Behavior Analyst, 36(2), 373-374.

Herrnstein, R. J. (1990). Rational choice theory: necessary but not sufficient. American Psychologist, 45(3), 356-367. doi:10.1037/0003-066x.45.3.356.

Houmanfar, R. A., \& Mattaini, M. A. (2015). Leadership and cultural change. Journal of Organizational Behavior Management, 35(1-2), 1-3. doi:10.1080/01608061.2015.1036645.

Hughes, S., \& Barnes-Holmes, D. (2016). Relational frame theory: the basic account. In R. D. Zettle, S. C. Hayes, D. Barnes-Holmes \& A. Biglan (Eds.), The Wiley handbook of contextual behavioral science. (pp. 129-178). Wiley-Blackwell.

Hursh, S. R. (2014). Behavioral economics and the analysis of consumption and choice. In F. K. McSweeney \& E. S. Murphy (Eds.), The Wiley Blackwell handbook of operant and classical conditioning. (pp. 275-305). Wiley-Blackwell.

Laties, V. G. (2008). The journal of the experimental analysis of behavior at fifty. Journal of the Experimental Analysis of Behavior, 89(1), 95-109. doi:10.1901/jeab.2008.89-95.

McDowell, J. J., \& Calvin, N. T. (2015). Against matching theory: predictions of an evolutionary theory of behavior dynamics. Behavioural Processes, 114, 14-25. doi:10.1016/j.beproc.2015.02.007.

Nevin, J. A., \& Shahan, T. A. (2011). Behavioral momentum theory: equations and applications. Journal of Applied Behavior Analysis, 44(4), 877-895. doi:10.1901/jaba.2011.44-877.

Pustejovsky, J. E. (2015). Measurement-comparable effect sizes for single-case studies of free-operant behavior. Psychological Methods, 20(3), 342-359. doi:10.1037/met0000019.

Pustejovsky, J. E., Hedges, L. V., \& Shadish, W. R. (2014). Design-comparable effect sizes in multiple baseline designs: a general modeling framework. Journal of Educational and Behavioral Statistics, 39(5), 368-393. doi:10.3102/1076998614547577.

Shadish, W. R. (2014). Statistical analyses of single-case designs: the shape of things to come. Current Directions in Psychological Science, 23(2), 139-146. doi:10.1177/0963721414524773.

Solomon, B. G., Howard, T. K., \& Stein, B. Ä. L. (2015). Critical assumptions and distribution features pertaining to contemporary single-case effect sizes. Journal of Behavioral Education, 24(4), 438-458. doi:10.1007/s10864-015-9221-4.

Vannest, K. J., \& Ninci, J. (2015). Evaluating intervention effects in single, Äêcase research designs. Journal of Counseling and Development, 93(4), 403-411. doi:10.1002/jcad.12038. 